Dept. of Microbiology,

Faculty of Veterinary Medicine,

Al-Baath University, Syrian Arab Republic.

\title{
DETECTION OF TOXOPLASMA GONDII IN SHEEP AND HUMAN IN HAMA SYRIA
}

(With 7 Tables)

By

\section{E.Z. ADI and A. ALKHALED}

(Received at 25/10/2010)

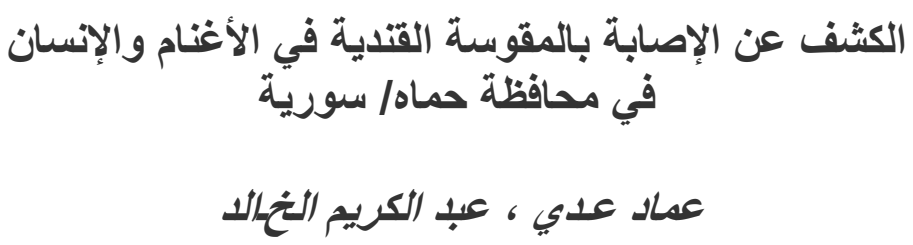

تحم㮆 فصص /291 / عينة مصلية لأغنام عواس من مناطق مختلفة في محافظة حماه، وذلك بهدف كثف نسبة الإصابة بالمقوسة القندية، حيث بلغت نسبة الإصابة

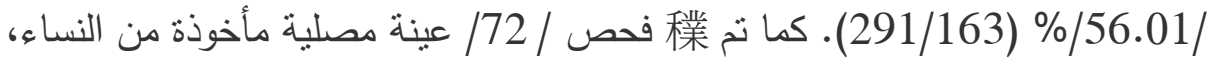
للهدف نفسه، وقد بلغت نسبة انتشار الإصابة فيها / 68.05/ \% (72/49). وقد أستخدم اختبار التراص السريع لاتكس واختبار التراص لاتكس في الأنابيب (البليت أو الأطباق ذات الحُفر )، وأعتبرت العيارات الإيجابية بدءاً من ( 64/1) عند الأغنام ، ومن ( 32/1)

عند الإنسان. ونم 稳 دراسة العلاقة بين نسبة انتشار الإصابة والمجموعات العمرية،

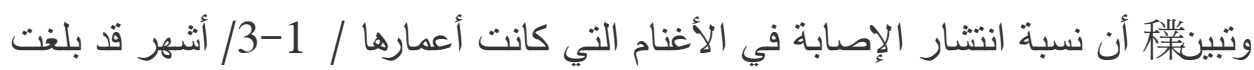

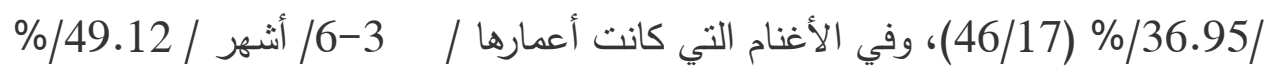

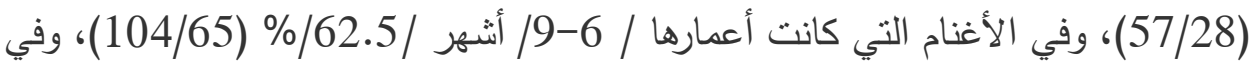

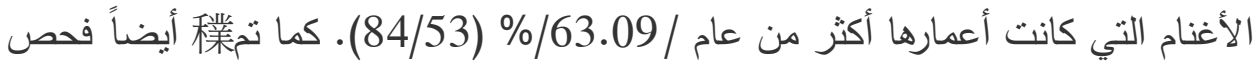

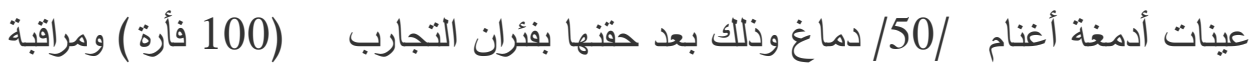

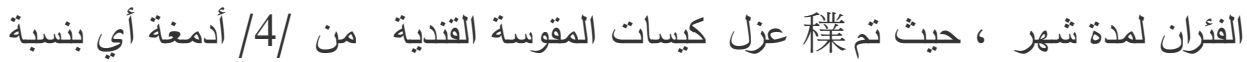

\section{SUMMARY}

$$
\% / 8 /
$$


A total of 291 serological samples of Ewassi sheep were collected from different regions in Hama Mhafazat, in order to detect the morbidity rate of Toxoplasma gondii. The reported morbidity rate was $56.01 \%$. Besides, 72 serological samples were collected from women for the same purpose, and the prevalence of infection was reported as 68.05\%. Latex rapid agglutination and Latex Plate- agglutination tests were used in the examination of samples. The Positive titers were started from titer 1/64 in sheep and cats and from 1/32 in human population. The relationship between morbidity rate and age of sheep categories was studied. It was reported that morbidity rate in ages between 1-3 months was $36.95 \%$; in ages between 3-6 months was $49.12 \%$, and in ages between 6-9 months old was $62.5 \%$. In sheep the infection was characterized in ages greater than one year, generally was $63.09 \%$. Experimental infection of mice using 50 brain sheep samples for one month revealed that 4 brains, (8\%) were positive for Toxoplasma-cyst.

Key words: Toxoplasmosis, T.gondii, sheep, latex agglutination tests.

\section{INTRODUCTION}

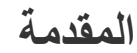

تعد المقوسة القندية (Tondii . T ) من الطفيليات الأوالي التي تتنمي إلى عائلة الكيسات اللحمية (Sarcocystidae)، وهي تصيب الحيوانات ذوات الدم الحار والطيور والإنسان ،

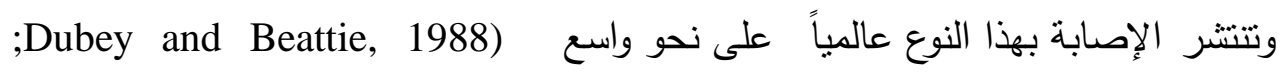
(Eckert et al., 2008 ، وتتميز المقوسة القندية بلهمية اقتصادية كبيرة عند المجترات

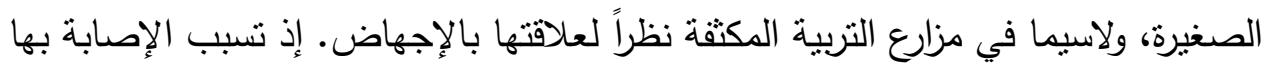

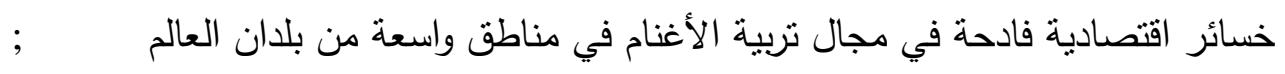
(Dubey and Beattie, 1988 Buxton et al., 2007) الأمراض المشتركة بين الإنسان و الحيوان ، ويعد عاملاً مسبباً للإجهاض في الأغنام (Dubey and Kirkbrid, 1984) ، ويسبب اضطرابات تتاسلية كولادة أجنة مجهضة فئنة (Beverly and Waston, 1961)، أو خراف ضعيفة (Perry et al., 1979). وقد تبين مدابن

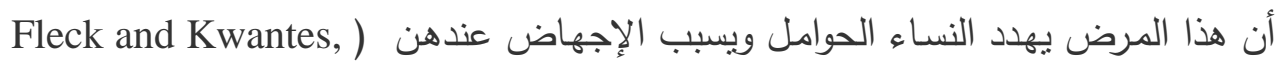


1980)، حيث وجد في مصر عيارات مرتفعة للمقوسة القندية في دماء النساء اللواتي كان لهن تماس مباشر مع القطط (Ghoneim et al.,1984). وتعد المقوسة القندية طفيليً مجبراً أو مجبراً ومخيراً ثنائي المثوى ، ويتطور داخل الخلية (Eckert et al., 2008)، أما بالنسبة للمسبب فتعد الكيسة البيضية ( Oocyst) هي مسبب الإصابة، وهي تتنمي إلى لى نمط البوغة الأسوية الكيسية ( Isospora)، التي تتتكل في المعي الدقيق للقطة (الثوي

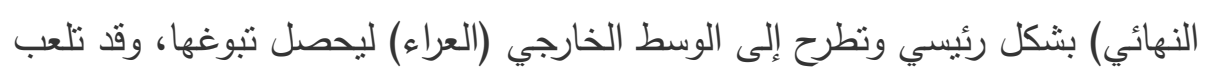

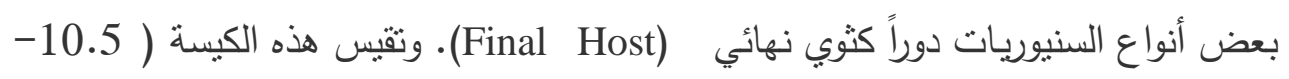

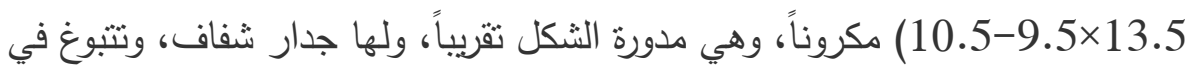
العراء وتتكل الكيسة البيضية المتبوغة التي تحنتوي على كيسين بوغيين في كل منها ( أبواغ، وهي تمثل الطور الخامج (Dubey, 2009; Eckert et al., 2008) و (الخالد 2002). وتمثل التربة مستودعاً للمقوسات (Frenkel and Ruiz,1981)، حيث يمكن للكيسات البيضية أن تبقى حية في التربة الرطبة المظللة لفترة أطول من عام Frenkel

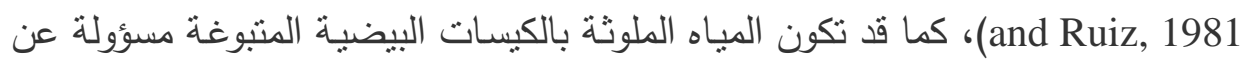

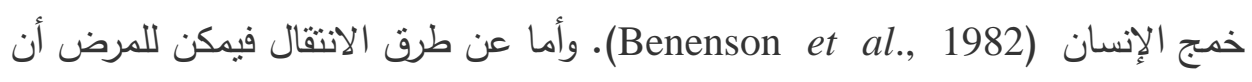

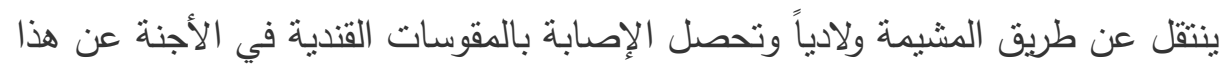
الطريق (30-40\%) في النساء التي تصاب لأول مرة خلال حملها الأول (1984,

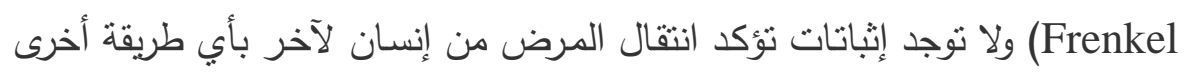

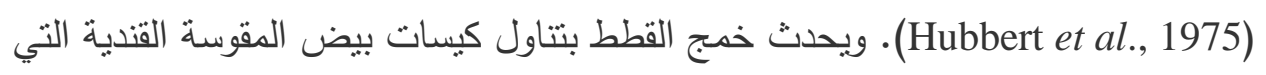
تبوغت في العراء أو بتتاول كيسات المقوسة القندية الموجودة في أعضاء جسم الجرذان ولحوم الحيوانات الأخرى التي تقوم بدور الثوي المتوسط (Mehlhorn et al., 2002)، أما لئاء خمج الأغنام وكذلك الجرذان فيتم بتتاول كيسات بيض المقوسة القندية المتبوغة مع بـ الإن الأعلاف أو الطعام والماء الملوثة بها (Eckert et al., 2008). ويحصل خمج الإنسان عن طريق تتاول كيسات بيضية منبوغة في العراء بعد إطراحها من القطط مع برازها الذي الأي

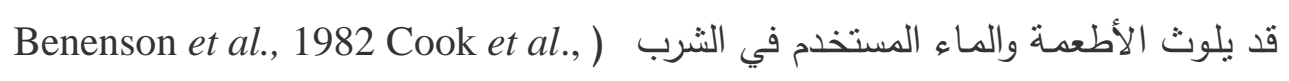
2000)، كما يحصل خمج الإنسان بالمقوسة القندية انطلاقاً من تتاول لحوم الأثوياء

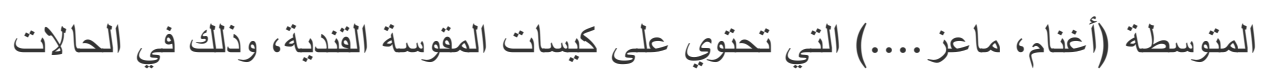


النيئة أو غير المطبوخة جيداً (Kean et al., 1969). كما قد يحصل خمج مخبري للعاملين في المخابر عندما يحقنون أنفسهم عرضياً بالحيوانات السريعة (Luft,1983)، وكذلك عن طريق نقل الدم (Acha,1989).

\section{: Prevalence of T. gondii الانتشار}

\section{1}

تختلف نسبة انتشار الإصابة بالمقوسة القندية عند الأغنام من مكان لآخر ،

ويتعلق ذلك بمدى انتشار القطط وبالعوامل البيئية والوبيئية.

حيث أنجزت عدة أبحاث علمية في القطر العربي السوري حول مدى انتشار

الإصابة بهذا الطفيلي عند الأغنام، ويمكن بيانها في هذا السياق وفق مايلي:

فحصت هبو في سوريا (حلب) عام (1999) /252/ عينة مصلية لأغنام

أعمارها أكثر من ست سنوات بطريقة اختبار التراص الدموي المباشر

\%/59.87 / HAT) Hemagglutination Antibody Test

حيث أكدت أن العوامل الوبيئية تلعب دوراً كبيراً في تأرجح نسبة الإصابة، ولاسيما وجود القطط ونظم التربية والإجراءات الصحية المتخذة ضمن الحظائر.

كما وجد El-Moukdad عام (2002) أن متوسط انتشار الإصابة بداء المقوسة ولنة

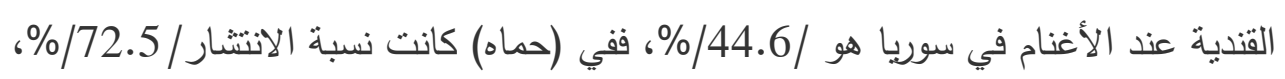

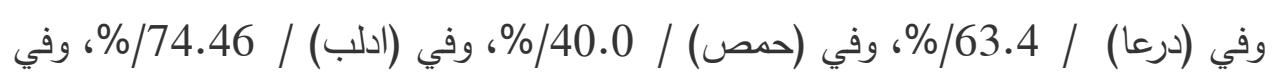

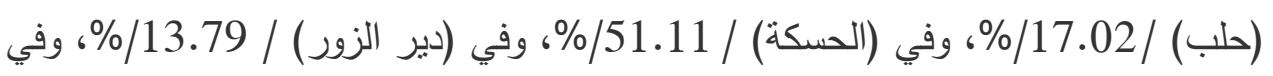

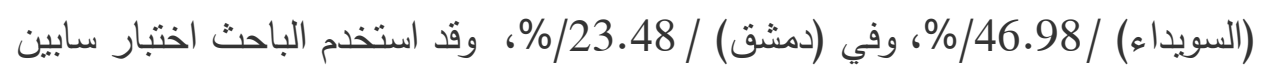

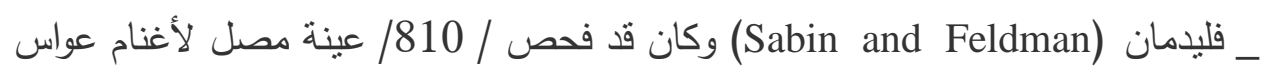
جُمعت من تسع محافظات سورية، وأكد El-Moukdad أن الخمج بالمقوسة القندية من الأسباب الرئيسة للإجهاض عند لكن الأغنام.

كما فحص الياسينو وشنكل عام ( 2003) /980/ عينة دم من أغنام مجهضة لإئة وترعى بشكل طليق وبأعمار أكثر من عامين بطريقة اختبار التراص لاتكس عامس 


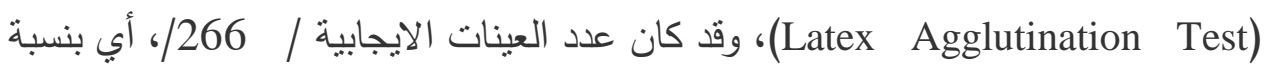

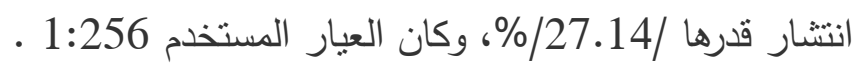

وأجرى الياسين وقطرنجي عام (2009) دراسة على / 133/ عينة مصل دم أغنام عواس بأعمار أكثر من سنة جمعت من المحطات الحكومية ذات النظام الإنتاجي المكثق /32/ عينة، ومن قطعان المربين ذات النظام السرحي الثائع في باديتي محافظتي حماة

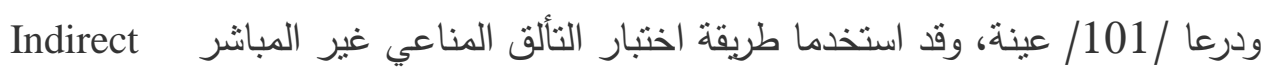
(IFAT) Fluorescent Antibody Test

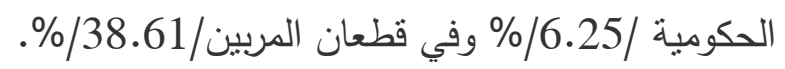

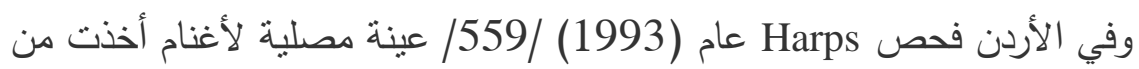

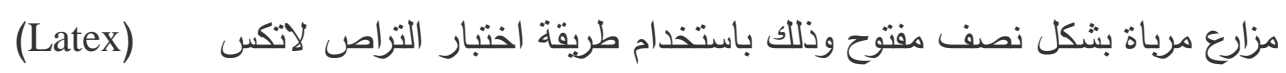

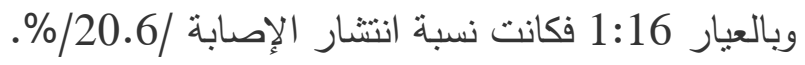
أما في مصر فقد فحص El-Ghaysh and Mansour عام (1994) /102/ عبنة مصلية لأغنام أخذت من مزارع مرباة بنظام تربية نصف مفتوح وحاوية على حالات

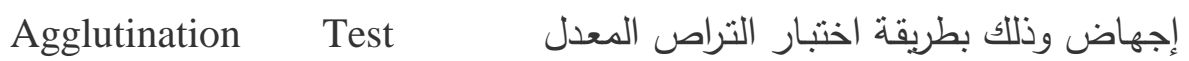
MAT)Modified كما فحص Shaapan ورفاقه عام (2008) في مصر / / 300/ عينة مصلية لأغنام مجهضة مذبوحة في المسالخ وذلك بطريقة اختبار التراص المعدل (MAT) بالعيار

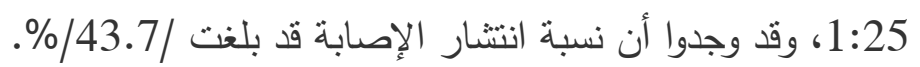

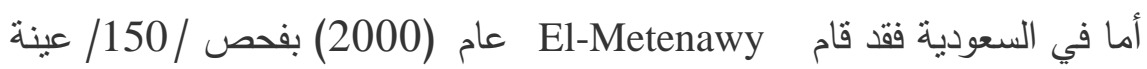
مصلية لأغنام مأخوذة من قطعان غير حاوية على حالات إجهاض بطريقة اختبار التراص الدموي غير المباشر Indirect Hemagglutination Antibody Test

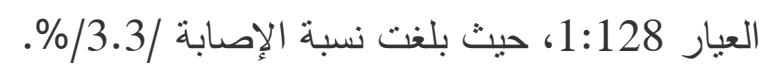
وفحص (Benkirane et al.,1990) في الدغرب / 304/ عينة مصلية لأغنام

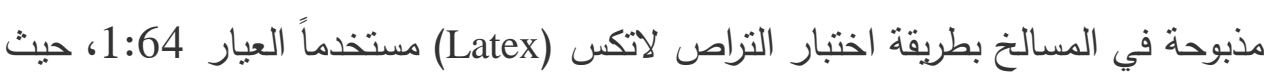
كثفوا الإصابة في /29/\% من العينات المفحوصة. 
أما في تركيا فقد قام Zeybek ورفاقه عام (1995) بفحص /1050/ عينة مصلية

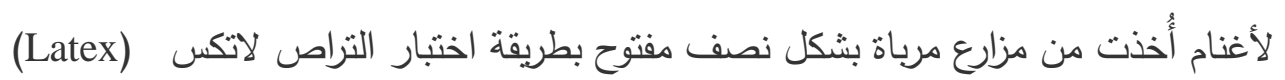

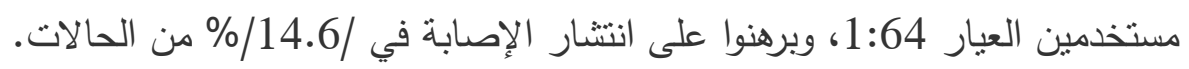
وفي إيران فحص Hoghooghi-Rad and Afraa عام (1993) /138/ عينة

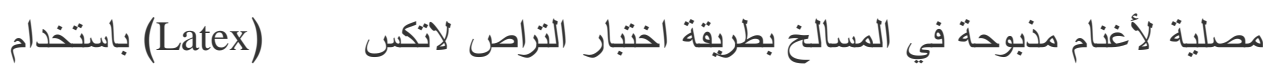

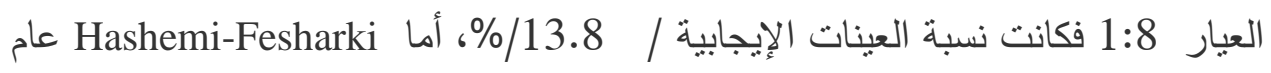
(1996) ونتيجة لفحوصاته في إيران كذلك لـ / 2209/ عينة مصلية لأغنام أخذت من الإنيل مزارع مرباة وفق نظام تربية نصف مفتوح مستخدماً نفس العيار السابق فقد كثف الإصابة في /24.3\% من العينات المفحوصة. وفي خارج المنطقة العربية والثرق الأوسط فقد نم إجراء فحوصات كثيرة حول نفس الطفيلي، ويمكن إيراد بعضاً منها: ففي البرازيل فحص Freire وزملائه عام (1995) /370/ عينة مصلية بطريقة

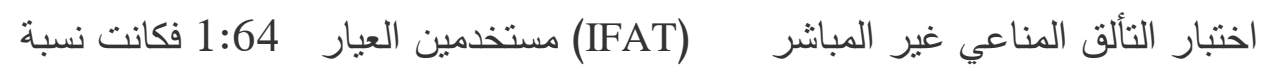
الإصابة /47.8\%. وقد لاحظوا أن انتثار الإصابة يزداد بازدياد العمر بينما لم يجدوا أي الي علاقة بين انتشار الإصابة والجنس. وفي نفس الدولة (البرازيل) فحص (Garcia et al.,1999) /228/ عينة مصلية بطريقة التألق المناعي غير المباشر (IFAT) مستخدمين نفس العيار السابق ( 1:64)،

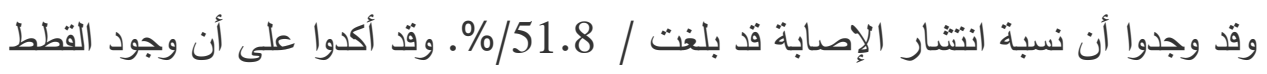

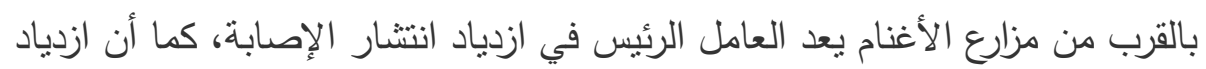

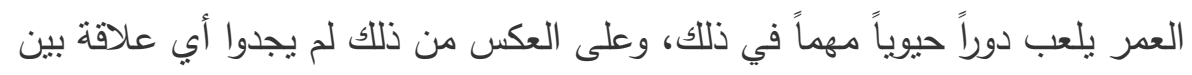
انتشار الإصابة والجنس.

أما في الهند فقد فحص Verma ورفاقه عام (1988) /164/ عينة مصلية لأغنام مأخوذة من قطعان لا يوجد فيها حالات إجهاض وذللك بطريقة اختبار التراص الدموي غير المباشر (IHAT) مستخدماً العيار .\%/8/ 
وفي السويد فحص (704/ (Lundén et al., 1992) عينة مصلية لأغنام

مأخوذة من قطعان لايوجد فيها حالات إجهاض وذلك بطريقة المقايسة المناعية المرتبطة بالأنظيم ELISA) Enzyme Linked Immuno-sorbent Assay)، حيث بلغت نسبة انتشار الإصابة / ب/19\%

وفي أمريكا فحص (1988) (Dubey and Welcome) عينة مصلية

لأغنام من مزارع نظام نصف مفتوح وفيها حالات إجهاض وذللك بطريقة اختبار التراص

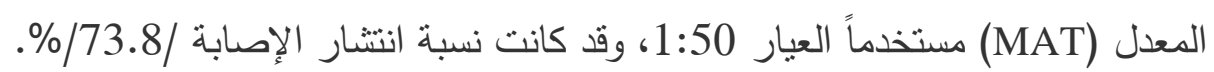

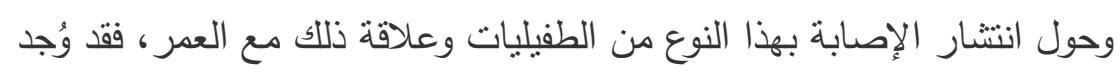

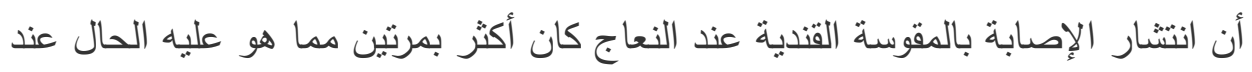

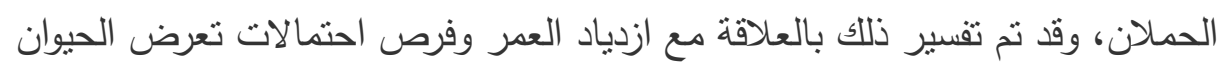
للخمج بشكل أكثر، وقد أكدت ذللك دراسات علمية عديدة منها:

; Figliuolo et al., 2004 Gorman etal., 1999 ; Lund’en et al., 1994 )

( Ragozo et al., 2008 ; Dume` tre et al., 2006 ; Rozette et al., 2005 وقام (Vesco et al., 2007) بفحص / 1961/ من الخراف من / 62/ مزرعة في

جنوب إيطاليا، وقد أشنار هؤلاء إلى أن وجود القطط في المزرعة التي تستخدم المياه

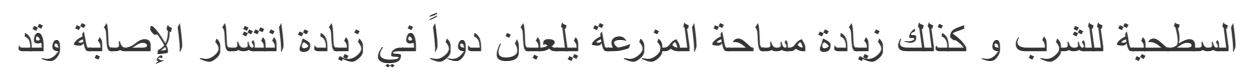
فسروا ذلك بقلة امكانبات السبطرة والتحكم بانتشار القطط في المزارع الكبيرة. وأجرى (Mainar et al., 1996) دراسة في اسبانيا استخلصوا منها أن وجود القطط وكذلك حالات الإجهاض السابقة كان لها دوراً كبيراً في زيادة انتشار الإصابة في دي

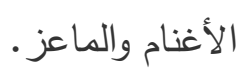

ووجد (Caballero-Ortega et al., 2008b) في المكسيك أن الارتفاع عن سطح

البحر ومساحة المزرعة تؤثران في نسبة الإصابة، حيث تتنشر الإصابة أكثر في

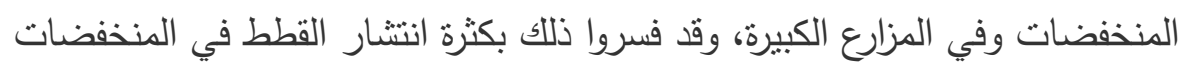
مقارنة مع المناطق المرتفعة. 2 
تمّ إجراء فحوصات مصلية عديدة لتشخيص وكثف الإصابة بطفيلي المقوسة القندية عندهم، ويمكن فيما يلي بيان بعضاً من تلك الدراسات والبحوث:

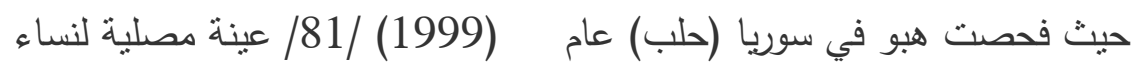

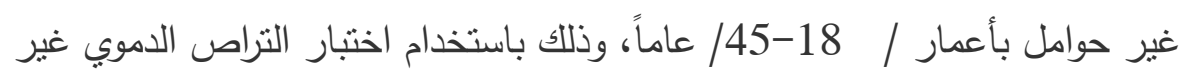

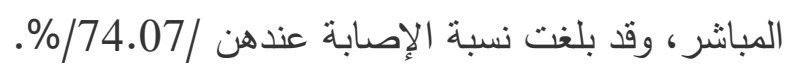

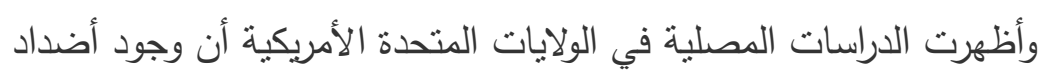
المقوسات القندية في الإنسان تراوحت بين / 3 - 40/ \% \%، وقد تم تفسير هذا الاختلاف بناءاً على عمر المجموعات المفحوصة والمنطقة الجغرافية (Feldman et al.,1965). أما في فنلندا (Lappalainen et al.,1992) فقد كانت نسبة الإصابة عند النساء

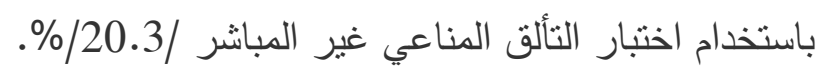

وفي دراسة مصلية لانتشار المقوسات القندية عند النساء في الدنمارك ( Lebech (et al.,1993) استخدم فيها اختبار التألق المناعي غير المباشر أظهرت النتائج أن نسبة الإصابة بلغت / /

كما فحص (J5940/350 / (Jenum et al.,1998 عينة مصلية لنساء حوامل في

النرويج باستخدام اختبار التألق المناعي غير المباشر لفحص أضداد المقوسة القندية فكانت نسبة الانتشار العام للمقوسة القندية / IgG) الإصابة ومجموعة عوامل (العمر ، الجنسية، المنطقة، عدد الأطفال) (الجدول رقم1 1).

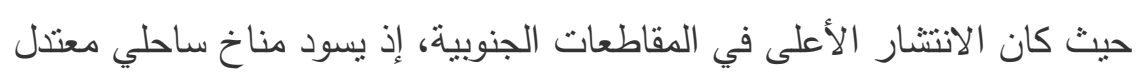

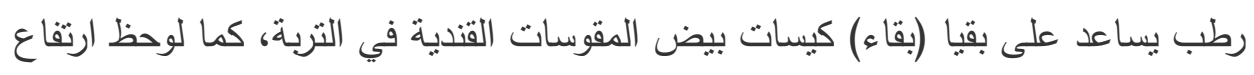

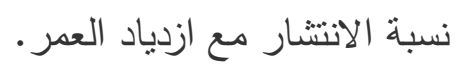

جدول 1: نسب انتشار المقوسة عند النساء في النرويج (Jenum et al.,1998).

\begin{tabular}{|c|c|c|c|c|c|c|c|}
\hline الانتشار & عدد & الانتشار & المنطقة & الانتثار & الجنسية & الانتشار & العمر (سنة) \\
\hline
\end{tabular}




\begin{tabular}{|c|c|c|c|c|c|c|c|}
\hline$\%$ & الأطفال & $\%$ & & $\%$ & & $\%$ & \\
\hline 8.8 & لايوجد & 6.7 & الشمال & \multirow{3}{*}{10} & \multirow{3}{*}{ نروجية } & 9.7 & $20>$ \\
\hline 10.2 & 1 & 9.7 & الوسط & & & 10.2 & $24-20$ \\
\hline \multirow{2}{*}{12.3} & \multirow{2}{*}{2} & 8.2 & الداخل & & & 10.1 & $29-25$ \\
\hline & & 13.4 & الجنوب & \multirow{3}{*}{22.6} & \multirow{3}{*}{ أجنبية } & 11 & $34-30$ \\
\hline \multirow{2}{*}{14.9} & \multirow{2}{*}{3 أوأكثر } & \multirow{2}{*}{13.2} & العاصمة & & & 14.3 & $39-35$ \\
\hline & & & (أوسلو ) & & & 16.7 & $40<$ \\
\hline
\end{tabular}

\section{MATERIALS and METHODS \\ مواد وطرائق العمل}

\section{1 - جمع العينات Collection of Samples:}

تمّ جمع العينات الدموية المأخوذة من الأغنام في أنابيب معقمة مفرغة من الهواء، (وذلك من الأغنام التي تربى في المنطقتين الثرقية والغربية لمحافظة حماه إضافة إلى منى الأغنام المرباة في منطقة المزارب التابعة لمدينة حماه). حيث أخذت عينات دم الأغنام من الوريد الوداجي ، وتم

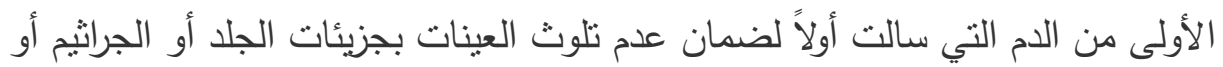

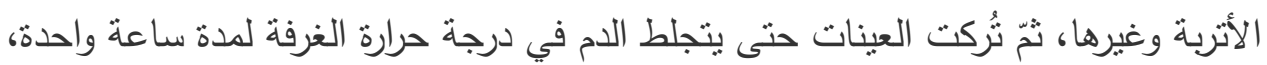

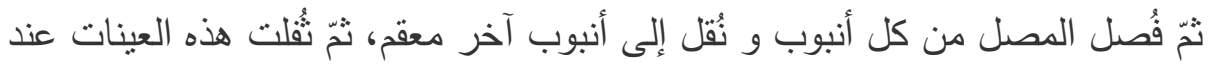
/3000/ دورة في الدقيقة لمدة / 15/ دقيقة، وبعد ذلك تمّ رشف المصل بوساطة ماصة إنة باستور المعقمة ونُقل إلى أنابيب إبندورف (Ebendorf)، التي تُشتعل لمرة واحدة فقط،

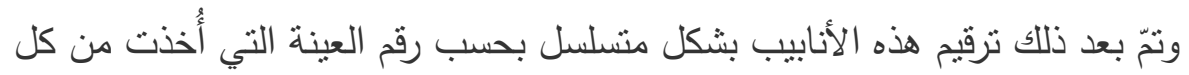
حيوان، وأجريت عليها الاختبارات مباشرة، أما في الحالات التي لم ينم إجراء الاختبار

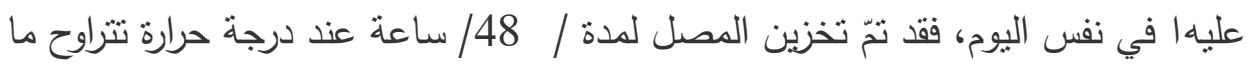

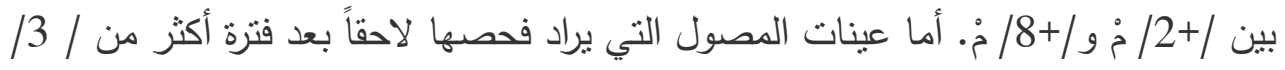

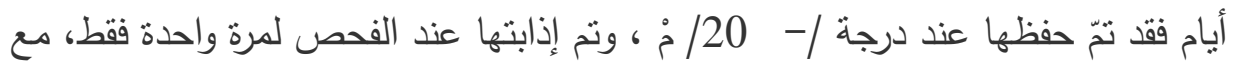


العلم أنه تم استبعاد عينات المصل التي ظهر فيها التحلل الاموي (Haemolysis) أو أي تلوث كما هو الحال في كل الاختبارات المصلية. :Tests 2

1-2 اختبار التراص لاتكس السريع Rapid Latex Agglutination Test أستخدم في هذا الاختبار كاشف (كيت-Tit) (TOXOCELL LATEX) من قبل شركة (BIOKIT)، وهذا الكاثف هو معلق من جسيمات لاتكس البوليسترينية ذات الحجم

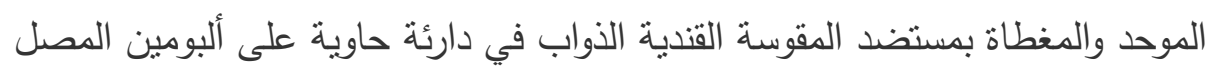
البقري (فيه أقل من 0,1\% أزيد الصوديوم). وتسمح هذه الجسيمات بمشاهدة مرئية لتفاعل (الضد- المستضد). بحيث أنه وفي حال حدوث تقاعل نتيجة لوجود مستضدات المقوسة في المصل فإن معلق لاتكس يتغير مظهره المتجانس ويحدث تراص واضح. وعند مزج

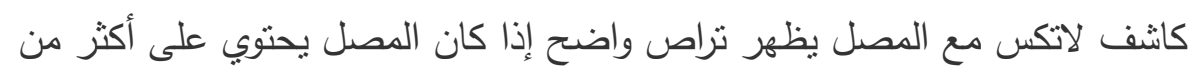
/10/وحدة دولية/مل/ من أضداد المقوسة تقريباً.

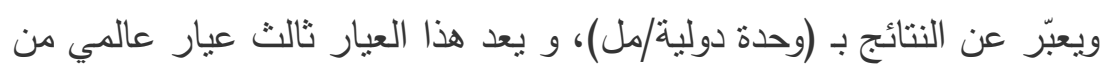

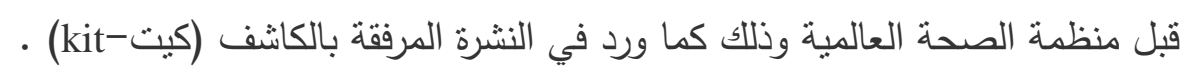

Reagents and Controls 1-2 1-1 الكواشف والثوالهد: إن (TOXOCELL LATEX) عبارة عن كاشف (كيت-Kit) يستععل مخبرياً

$$
\text { لكثف الإصابة بداء المقوسات ويحتوي على: كاشف لاتكس : المشار إليه أعلاه. }
$$

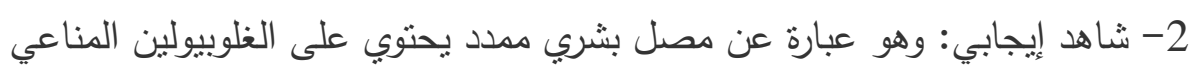

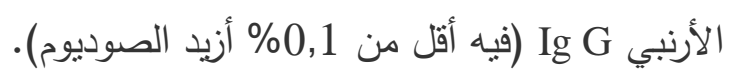

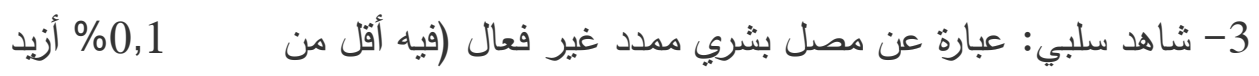

$$
\text { الصوديوم). }
$$

4- شرائح: /18/ شريحة تحتوي كل منها /6/ حفر بحيث يتم وضع في الحفرة /ا، 2 /

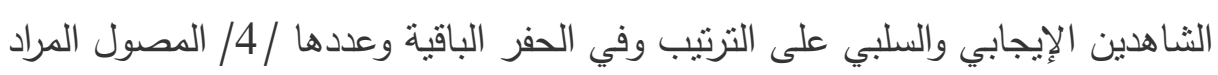


:Storage 2-1-2

تحافظ الكواثف على فعاليتها حتى نهاية التاريخ المحدد لصلاحيتها والددون على الكي بطاقة الكاشف (كيت-Kit)، وذلك عند الحفظ في درجة حرارة مابين / + 2 / و / مئوية.

(كit-3-1-2 مواد اخرى غير موجودة في علبة الكاثف (كيث) Materials Required But Not Provided مص آلي ، رجاجة، عيدان للمزج، مؤقتة زمنية .

: Test Procedure 4-2-2 طريقة العمل 1- يجب أن تصل درجة حرارة الكاثف إلى درجة حرارة الغرفة. 2- ينت وضع /50/ ميكروليتز من المصول المراد فحصها في كل حفرة من حفر الثريحة (أو قطرة من الثاهد ).

3- يتم رج عبوة الكاثنف ووضع قطرة منه إلى جانب قطرة العينة . 4- يتم مزج كلا القطرتين بواسطة ملوق (loup) المزج حتى تغطي كامل الحفرة.

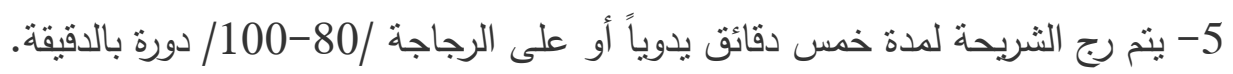

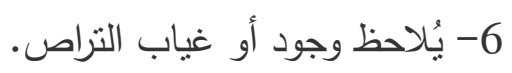

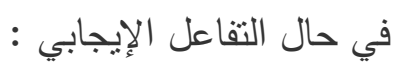

يُلاحظ وجود تراص +3 : خثرات كبيرة على خلفية واضحة. +2+ 2+ خثرات متوسطة مع سائل عكر قليلا .

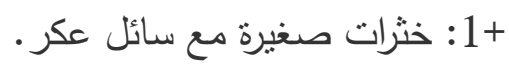
في حال التفاعل السلبي: يُلاحظ غياب التراص ويكون المعلق متجانساً. 2-2 اختبار التراص لاتكس في الأنابيب (البليت أو الأطباق ذات الحُفر) Latex Agglutination Test In Plate

ليعتد هذا الاختبار على الكثف عن الأضداد IgG، وهو اختبار تراص

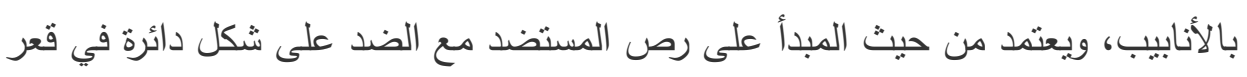

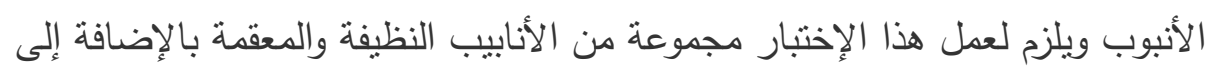


بليتة (plate) وهي تحتوي /96/ حفرة مقعرة على شكل حرف ( U) بالإضافة إلى حاضنة

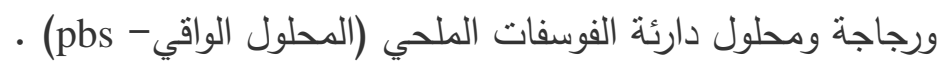

\section{:Test Procedure 1-2-2}

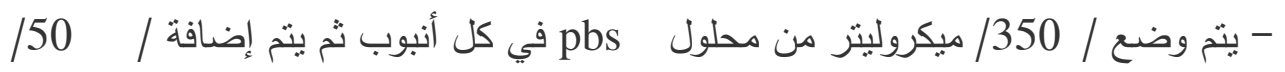
ميكروليتر من كل عينة إلى كل أنبوب مع الحفاظ على الترقيم ثم يتم المزج جيداً . إن البليتة تحتوي /96/ حفرة على شكل /12/ صف و و/8/أعمدة . - يتم وضع/25/ ميكروليتز محلول pbs في كل حفرة من حفر البليتة.

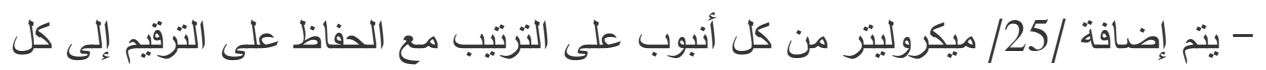
حفرة من حفر الصف الأول.

- يتم التمديد بأخذ / 25/ ميكروليتر من كل حفرة من حفر الصف الأول إلى الحفرة

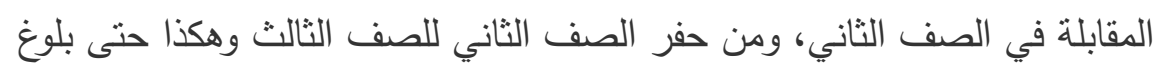
الصف الثامن، حيث يُؤخذ من كل حفرة / 25/ ميكروليتر وثُرمى خارجا، وهكذا يكون وني العيار من الصف الأول إلى الصف الثامن وفق مايلي:

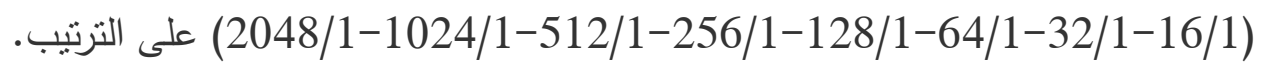
- يُضاف /25/ ميكروليتز من الأنتيجين إلى كل حفرة من حفر البليتة.

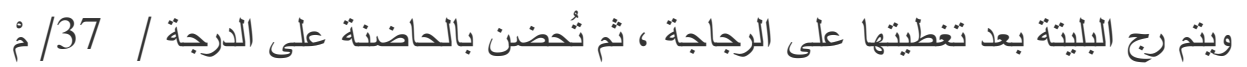
لمدة /4/ ساعات ويتم عقب ذلك قراءة نتائج التفاعل. ونشبر هنا إلى أن هذا الاختبار قد طبق فقط على العينات الإيجابية.

\section{: Reading Results قراءة النتائج}

- تعد النتيجة إيجابية في حال حصول تراص، ويكون العيار إيجابياً بالنسبة للحيوانات

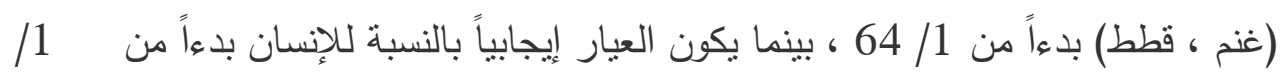

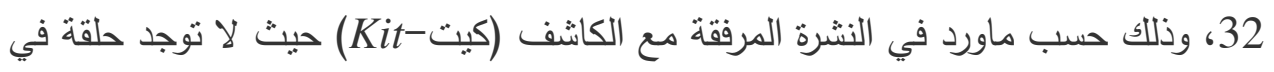
قاع الحفرة، وقد يلاحظ في بعض الأحيان وجود حلقة طرفية رقيقة ويعطى العيار للتمديد الأول الذي يبذو بشكل حلقة محيطية عريضة. - تعد النتيجة سلبية في حال عدم حصول تراص دموي، حيث يلاحظ وجود حلقة قد تكون واسعة إلى قليلة الاتساع • 


\section{3-3 عزل المقوبة القتدية من أنسجة الحيوانات}

\section{Isolation of Toxoplasma gondii from Animal Tissues}

1 - يتم إزالة الدهون والأنسجة المتصلة من المادة المراد فحصها.

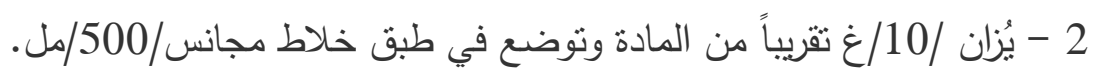
3 - ينم فرم القطع النسيجية جيداً بمقص.

4 - يتم إضافة / 100/مل تقريباً من المحلول الملحي ( pbs) فوق بمع العينة السابقة الذكر في وعاء من أجل التجانس.

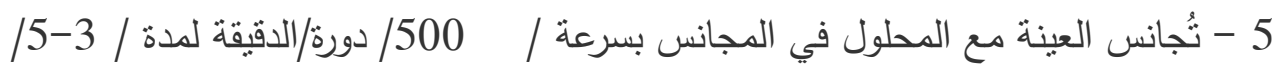
دقائق مع وجود التلج للتبريد. 6 - يتم فلترة المعلق من خلال طبقتنين من الثشاش في أنابيب التثقيل.

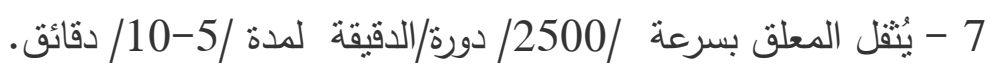
8 - يتم استبعاد الطافي بعد التثفيل.

9 - يُعلق الراسب بعدة مليلترات من السالين الحاوي على مضادات حيوية (بنسلين، ستربتومايسين) .(St:100 u /ml, PN:1.000u/ml) 10 - يتم حقن من (1/2-1) مل من كل معلق ب/3-3/15/ فأر .

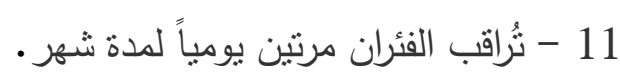

فحص الإصابة بالمقوسة القندية في الفئران المحقونة: Examination of Toxoplasma-Infection in Mice Inoculated 1 - في حالة ظهور أعراض سريرية:

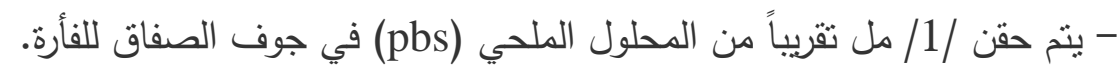

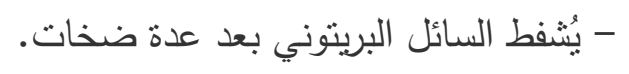

- يتم تقطير كمية قليلة من السائل البريتوني على الثريحة وتُوضئح الساترة فوقها. - ينم الفحص من أجل وجود الحيوانات السريعة للمقوسة القندية على التكبير / 200 أو 400/ *فصص إضافي: لطاخة ملونة للسائل البريتوني (صبغة جيمزا) 
2 - في حالة موت الفئران أثناء فترة المراقبة:

(1) إذا ماتت مباشرة: يتم فحص السائل البرينوني و /أو السائل الجنبي بواسطة اللطخة الطازجة أو الملونة.

$$
\text { (2) الموت أبكر من /3/ أسابيع بعد الحقن: }
$$

- يتم جمع قطعة صغيرة (تقربياً 2 سم) من العقدة اللمفاوية المساريقية أو الرئة

$$
\text { وتُوضع على الثربحة. }
$$

- تُقرم القطعة جيداً بواسطة المقص.

- يتم إضافة قطرة واحدة من المحلول الملحي ( مbs) على النسيج المحضر وتُزال

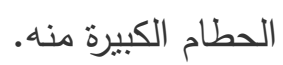

- يُغطى المعلق النسيجي بواسطة ساترة. - يتم الفحص من أجل وجود الحيوانات السريعة للمقوسة القندية على التكبير / 200 أو 400/

$$
\text { (3) موت الفئران بعد أكثر من /3/ أسبوع بعد الخمج: }
$$

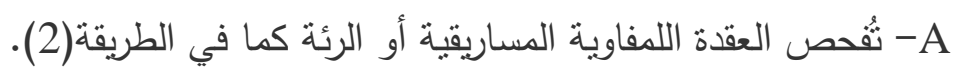

B يُفحص الدماغ للكثف عن وجود كيسات المقوسة القندية:

$$
\text { - يُؤخذ الدماغ. }
$$

- يتم قطع جزئين صغيرين من المادة السنجابية من الدماغ و توضعان على الثريحة.

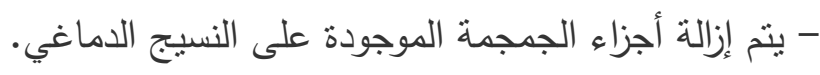

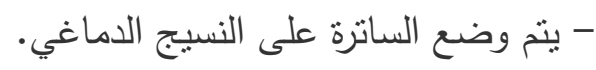
- يتم هرس النسيج بالضغط بواسطة الأنامل.

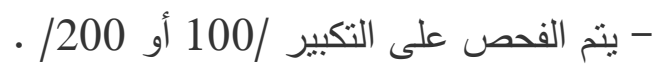

" فحص الكيسات: يكون مفيداً جداً خصوصاً في حالة الموت للفئران بعد أكثر من

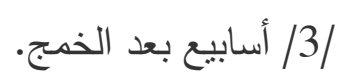
3- في حالة البقاء على قيد الحياة:

A يتم جمع دم عند قتل الفئران من أجل فحص وجود أضداد المقوسات.

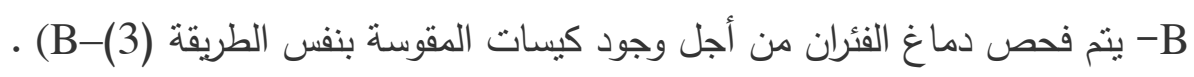




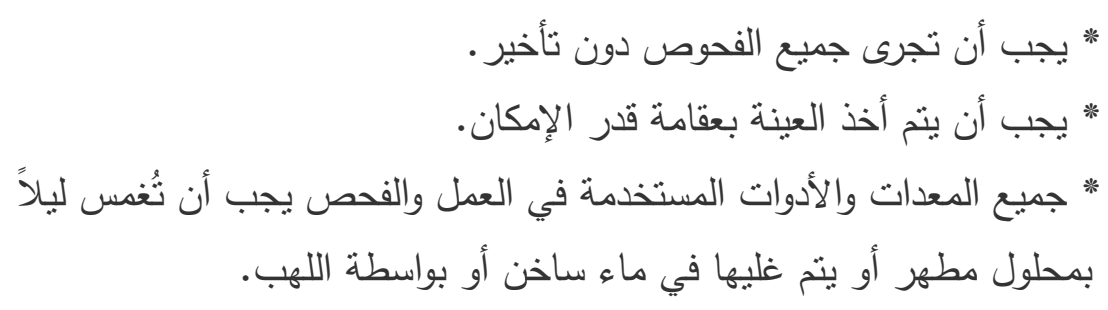

RESULTS

النتائجج

في إطار هذا البحث تم 稳 فحص /291 / عينة مصلية المصلية لأغنام عواس،

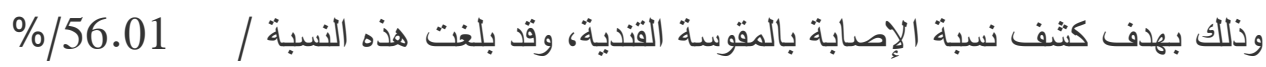

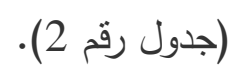

جدول 2 : نسبة انتنار الإصابة بالمقوسة القندية في الأغنام وذلك بحسب اختبار التراص

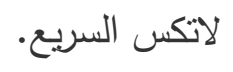

\begin{tabular}{|c|c|c|c|c|}
\hline \multicolumn{2}{|c|}{ العينات السلبية } & \multicolumn{2}{|c|}{ العينات الإيجابية } & عدد العينات \\
\hline النسبة المئوية\% & العدد & النسبة المئوية\%\% & العدد الع & \\
\hline 43.99 & 128 & 56.01 & 163 & 291 \\
\hline
\end{tabular}

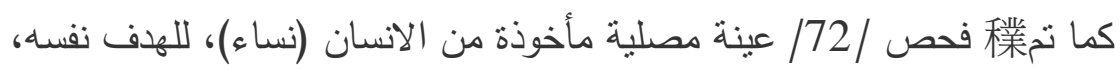

$$
\text { وقد بلغت نسبة انتشار الإصابة عندهن (68.05)\% (جدول رقم 3). }
$$

\begin{tabular}{|c|c|c|c|c|}
\hline & & & \multicolumn{2}{|c|}{ لاتكس السريع. } \\
\hline \multicolumn{2}{|c|}{ العينات السلبية } & \multicolumn{2}{|c|}{ العينات الإيجابية } & عدد العينات \\
\hline النسبة المئوية\%\% & العدد & النسبة المئوية\% & العدد & \\
\hline 31.95 & 23 & 68.05 & 49 & 12 \\
\hline
\end{tabular}

جدول 3: نسبة انتشار الإصابة بالمقوسة القندية في الانسان وذلك بحسب اختبار التراص 
وقد أستخدم اختبار التراص السريع لاتكس واختبار التراص لاتكس في الأنابيب

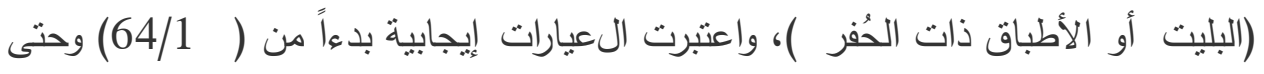

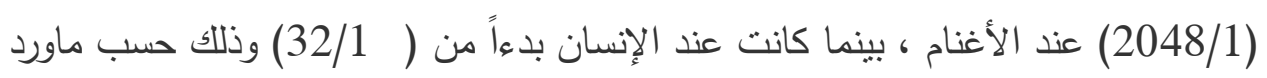

$$
\text { في نشرة الكاثف (كيت Kit). }
$$

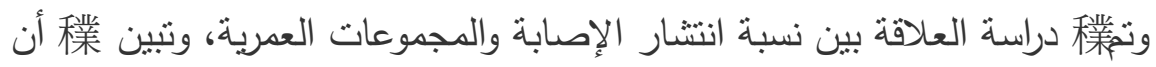

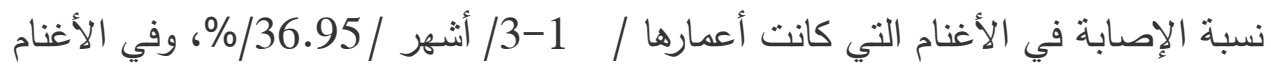

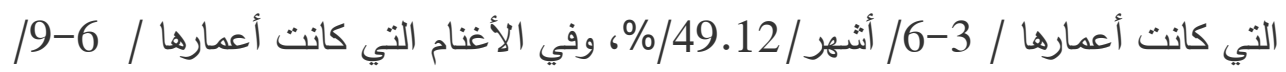
أنثهر/62.5\%، وفي الأغنام التي كانت أعمارها أكثر من عام / 63.09/63\% (جدول رقم

جدول 4: نسبة انتثار الإصابة بالمقوسة القندية في الأغنام وذلك بحسب اختبار التراص لاتكس السريع حسب العمر .

\begin{tabular}{|c|c|c|c|}
\hline النسبة المئوية\%\% & العدد الإيجابي & العدد المفحوص & 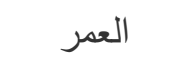 \\
\hline 36.95 & 17 & 46 & 1-3أشهر \\
\hline 49.12 & 28 & 57 & 3-6 أشنهر \\
\hline 62.5 & 65 & 104 & 6-9 أشثر \\
\hline 63.09 & 53 & 84 & أكثز من عام \\
\hline
\end{tabular}

أما نسب الإصابة بالمقوسة القندية في الأغنام بحسب عيارات الأضداد في حفر

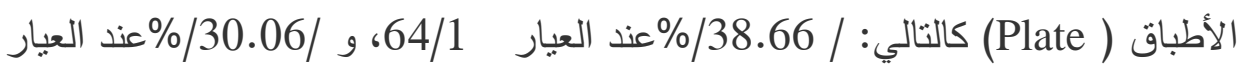

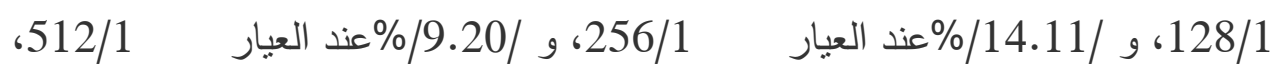

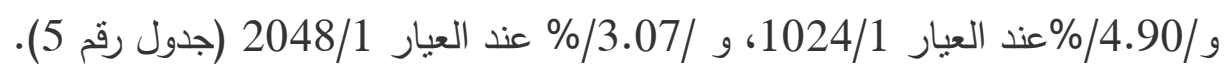
جدول 5: نسب انتشار الإصابة بالمقوسة القندية في الأغنام بحسب عيارات الأضداد في

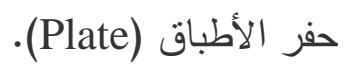

\begin{tabular}{|l|l|l|l|l|l|l|l|}
\hline الأضداد \\
\hline
\end{tabular}




\begin{tabular}{|c|c|c|c|c|c|c|c|}
\hline 163 & 5 & 8 & 15 & 23 & 49 & 63 & عدد العينات \\
\hline$\% 100$ & $\% 3.07$ & $\% 4.90$ & $\% 9.20$ & $\% 14.11$ & $\% 30.06$ & $\% 38.66$ & المئوية النسبة \\
\hline
\end{tabular}

أما عند الإنسان (نساء) فقد بلغت نسب انتشار الإصابة بالمقوسة القندية بحسب عيارات الأضداد في حفر الأطباق ( Plate) فقد كانت كالتالي: / 18.37\% عند العيار

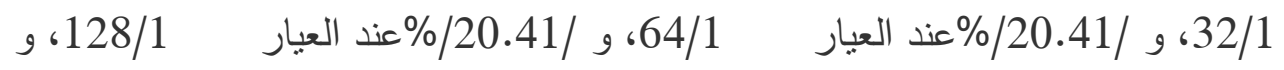

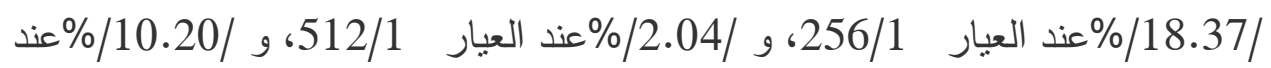
العيار 1024/1، و /2048/1 / (جدول رقم 6) العيار

جدول 6: نسب انتشار الإصابة بالمقوسة القندية في الانسان بحسب عيارات الأضداد في حفر الأطباق (Plate).

\begin{tabular}{|c|c|c|c|c|c|c|c|c|}
\hline المجموع & $\begin{array}{c}/ 1 \\
2048\end{array}$ & $\begin{array}{c}/ 1 \\
1024\end{array}$ & $\begin{array}{c}/ 1 \\
512\end{array}$ & $\begin{array}{c}/ 1 \\
256\end{array}$ & $\begin{array}{c}/ 1 \\
128\end{array}$ & $64 / 1$ & $32 / 1$ & الأضدات \\
\hline 49 & 5 & 5 & 1 & 9 & 10 & 10 & 9 & عدد العينات \\
\hline$\% 100$ & $\begin{array}{c}10.20 \\
\%\end{array}$ & $\begin{array}{c}10.20 \\
\%\end{array}$ & $\begin{array}{c}2.04 \\
\%\end{array}$ & $\begin{array}{c}18.37 \\
\%\end{array}$ & $\begin{array}{c}20.4 \\
\% 1\end{array}$ & $\begin{array}{c}20.41 \\
\%\end{array}$ & $\begin{array}{c}18.3 \\
\% 7\end{array}$ & المئويةبة النسبة \\
\hline
\end{tabular}

كما تمياق稀 بعد حقن الأدمغة المعاملة مع المحلول الواقي بفئران التجارب /100/ فأرة ومراقبة الفئران

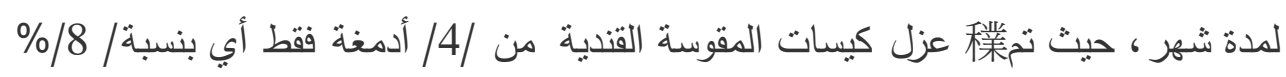
(جدول رقم 7) (

جدول 7: نسب انتشار الإصابة بالمقوسة القندية في أدمغة الأغنام بعد الحقن في فئران التجارب.

\begin{tabular}{|c|c|c|c|c|}
\hline \multicolumn{2}{|c|}{ العينات السلبية } & \multicolumn{2}{|c|}{ العينات الإيجابية } & عدد الأدمغة \\
\hline النسبة المئوية\% & العدد & النسبة المئوية\% & العدد & 50 \\
\hline
\end{tabular}




\begin{tabular}{|l|l|l|l|l|}
\hline 92 & 46 & 8 & 4 & \\
\hline
\end{tabular}

\section{التحليل الإحصائي والويائي لنتائج البحث:}

أستخدمت تقنية اختبار بيرسون مربع كاي ( Pearson's Chi Square) لمقارنة النسب المئوية لمعدلات الإصابة ومعايير الأضداد الإيجابية. وقد سجلت الدراسة النتائج

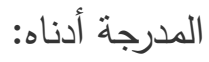

- بمقارنة الفروقات بين النسب المئوية للعينات الإيجابية والسلبية في الأغنام (اختبار التراص لاتكس السريع) لم توجد هناك فروقات معنوية بين كل من من العينات الإيجابية

$$
\text { والسلبية (X2) }
$$

- بمقارنة النسب المئوية لمعدلات الإصابة بين الفئات العمرية في الأغنام فقد سُجلت

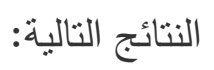

1- وجدت هناك فروقات معنوية واضحة في معدلات الإصابة بين الفئة العمرية الأولى

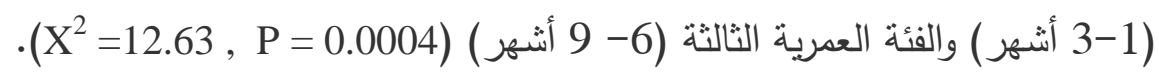
2- وجدت هناك فروقات معنوية واضحة في معدلات الإصابة بين الفئة العمرية الأولى والى

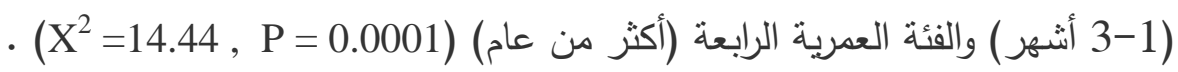
3- وجدت هنالك فروقات معنوية بسيطة في معدلات الإصابة بين الفئة العمرية الثانية

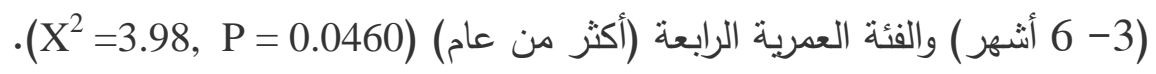

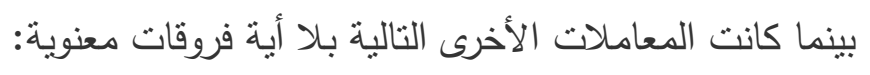

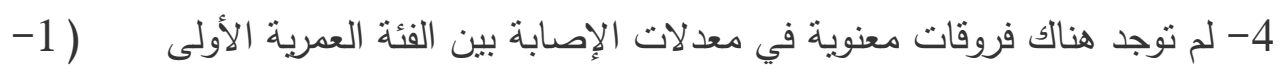

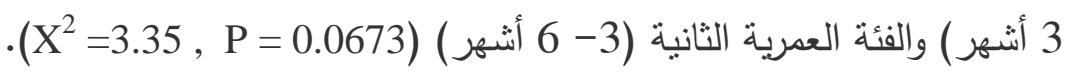

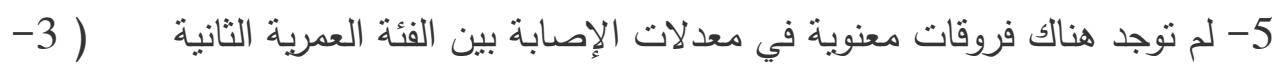

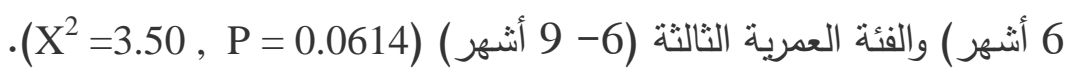

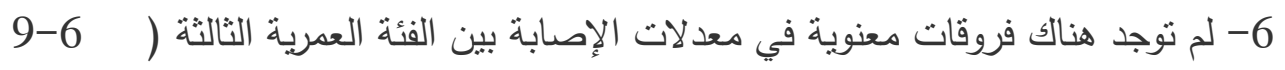
أثنهر) والفئة العمرية الرابعة (أكثر من عام) (X) (X) 
- بمقارنة الفروقات بين النسب المئوية للعينات الإيجابية والسلبية في الانسان (اختبار

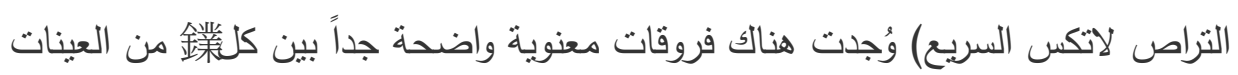

$$
\text { الإيجابية والسلبية (X) }
$$

- كما تم 㮆 حساب المتوسط الهندسي للمعايير الإيجابية للإصابة بالمقوسة القندية في الأغنام (اختبار التراص لاتكس في الأنابيب) حسب (Martine et al., 1987):

$$
G m=\sqrt[n]{x 1 \times x} 2 \ldots \ldots \ldots . . . . x n
$$

Gm Titers $=362.0387$

إذ وجدت هناك فروقات معنوية واضحة جداً بمقارنة المعايير الإيجابية التي تقع

دون مستويات معيار المتوسط الهندسي مع المستويات التي تقع بشكل أعلى من قيمة

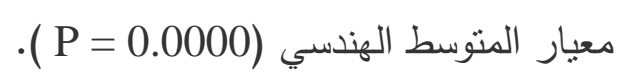

- كما تم 㮆 حساب المتوسط الهندسي للمعايير الإيجابية للإصابة بالمقوسة القندية في

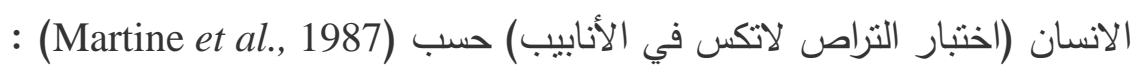

$$
G m=\sqrt[n]{x 1 \times x} 2 \ldots \ldots \ldots \ldots n
$$

Gm Titers $=256$

حيث وجدت هناك فروقات معنوية بسيطة بمقارنة المعايير الإيجابية التي تقع دون

مستويات معيار المتوسط الهندسي مع المستويات التي تقع بشكل أعلى من قيمة معيار

$$
\text { المتوسط الهندسي (P = 0.0009). }
$$

- بمقارنة الفروقات بين النسب المئوية للعينات الإيجابية والسلبية (طريقة الحقن في فئران

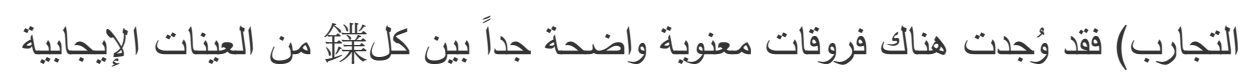

$$
\text { والسلبية (X) }
$$

\section{DISCUSSION}

\section{المناقشـة}

بينت نتائج هذا العمل أن نسبة انتشار الإصابة بالمقوسة القندية عند الأغنام المفحوصة / 166.01\% (163 عينة ايجابية من أصل 291 عينة مصل مفحوصة) بلابهة (جدول رقم2). 
وتعد هذه النسبة أعلى مما ورد في دراسة الياسين وقطرنجي عام (2009) والتي

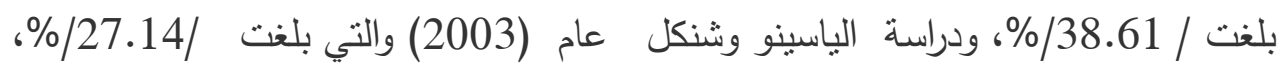

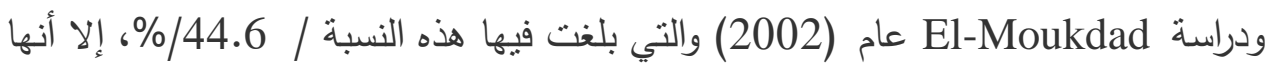
كانت قريبة ومنوافقة تقريباً مع دراسة هبو (1999) التي وجدت نسبة انتشار قد بلغت /59.87\% / وقد يمكن تفسير ذلك عموماً باختلاف مناطق الفحوصات، والعوامل

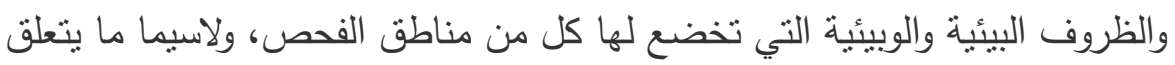
بظروف الطقس والأمطار ودرجتي الرطوبة والحرارة وكذلك وجود الثوي النهائي (القطط).

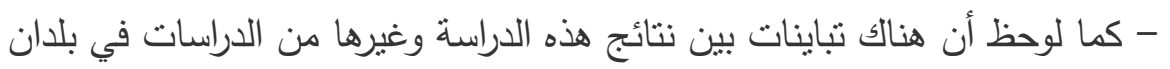

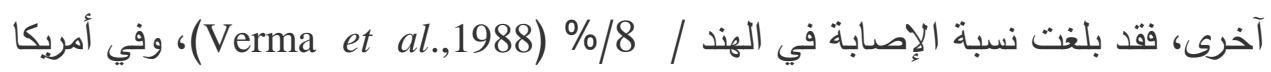
Benkirane et ) \%/29/Dubey and Welcome, 1988) \%/73.8/

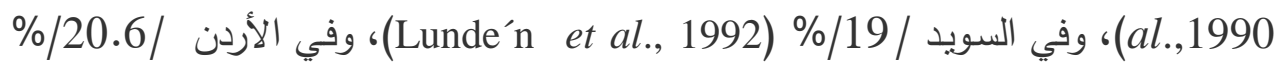

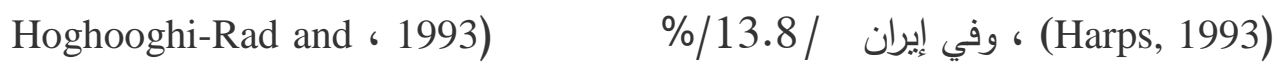
El-) \%/49 / (Hashemi-Fesharki، 1996) \%/24.3/، (Afraa \%/43.7/، (Ghaysh and Mansour, 1994

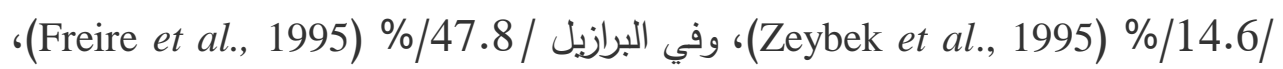

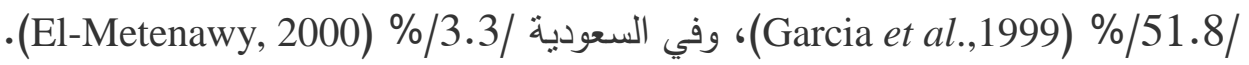
ولا شك بأن عوامل الطقس والمناخ التي تساهم في تبوغ واستمرارية حياة الكيسة البيضية المتبوغة، ومدى وجود القطط كثوي نهائي بطرح الكيسات البيضية تلعب الدور المحوري والرئيس في ذللك، ولايمكننا في هذا المجال إغفال طرائق الفحص ونوعية الكواثف وأحياناً نسب التمديد التي قد تلعب دوراً في هذا المجال. كما يبين (الجدول رقم

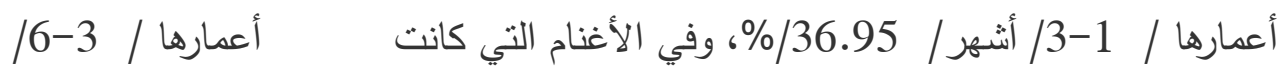

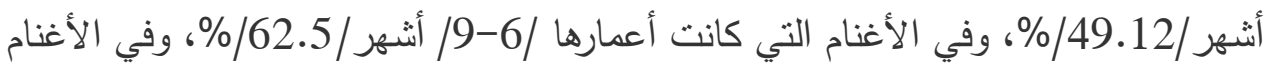

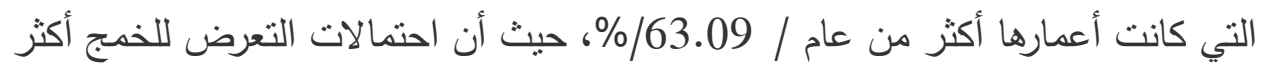
ولفترة أطول بالنسبة للحيوانات الأكبر سناً، وذلك بتتاول كيسات بيض المقوسة القندية التي Freire $e t$ تتبوغ في العراء هو العامل الرئيس في ذلك، وقد بين ذلك كل من 
(al.,1995)، و (Garcia et al., 1999)، بالإضافة إلى دراسات وأبحاث آخرى.

; Figliuolo et al., 2004 ; Gorman et al., 1999 ; Lund'en et al., 1994) .(Ragozo et al., 2008 ; Dume` tre et al., 2006 ; Rozette et al., 2005 أما عند الانسان (نساء)، فقد بلغت نسبة انتشار الإصابة وبحسب ماورد في

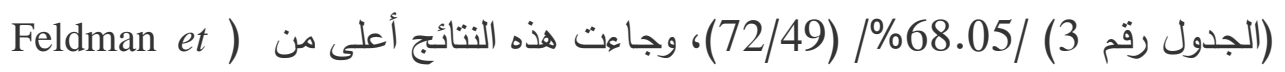

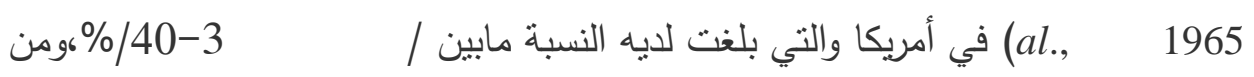
(Lappalainen et al.,1992) في فلندا والتي بلغت النسبة في دراستهم /

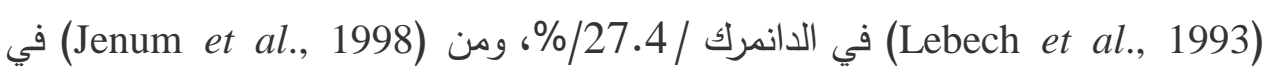
النرويج /10/\%، بينما كانت هذه النتائج أقل من دراسة هبو (1999) التي وجدت نسبة

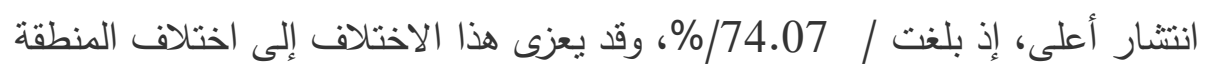
الجغرافية واختلاف الأعمار وكذللك اختلاف أنواع الأطعمة والمواد الغذائية (اللحوم والخضار) عند الثعوب وعاداتها في تربية القطط في المنازل من عدمه.

\section{CONCLUSIONS and RECOMMENDATIONS} الاستنتاجات والتوصيات

تبين من نتائج البحث وجود إصابة بالمقوسات القندية في محافظة حماه، ولهذا

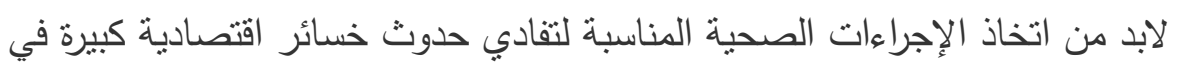

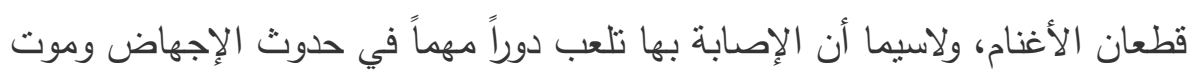

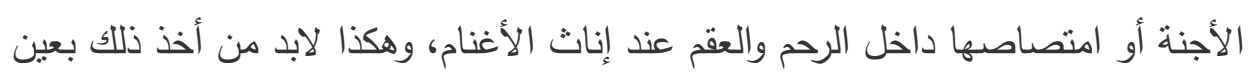

الاعنبار عند دراسة الإجهاض في قطعان الأغنام، وبذلك لابد من إيلاء النقاط التالية أهمية في ذلك: الاعنار عند

1 - يتوجب العمل لإبعاد القطط عن محطات ومواطن التربية والرعي للأغنام، نظراً لأنها

تمثل الثوي النهائي الرئيسي والمستودع الهام للطفيلي • لخدئ

2 - أخذ صحة الانسان بعين الاعتبار ، ولاسيما بإتباع وسائل التصحيح (الصحة العامة)

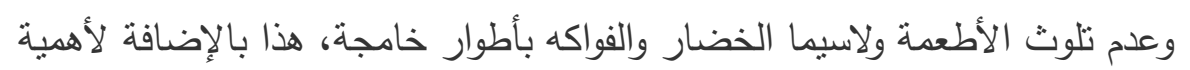


طبخ وطهي اللحوم بشكل جيد، بحيث يتم تجنب الخمج بكيسات المقوسة (Cysts) التي

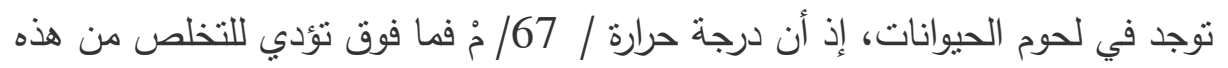

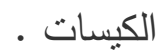

3 - معالجة القطط التي تربى في المنازل أو في مراكز التربية والتسمين.

\section{REFERENCES}

\section{المراجع}

\section{: Arabic References المراجع العربية}

الخالد عبد الكربيم (2002): الطفيليات الطبية كلية الطب البشري/جامعة البعث/ الجمهورية

$$
\text { العربية السورية. }
$$

الباسبن ، عبد المنعم ، قطرنجي ، محدد محسن ( 2009): بعض العوامل المؤثرة في انتثار المقوسة القندية عند المجترات الصغيرة في محافظتي حماة ودرعا، المجلة الصنة

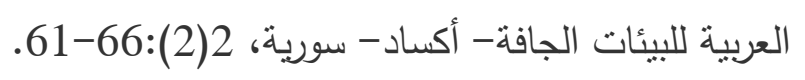

الباسينو ، باسسين وفرنك شنكل ( 2003): دراسة عن وجود وانتشار داء المقوسات القندية

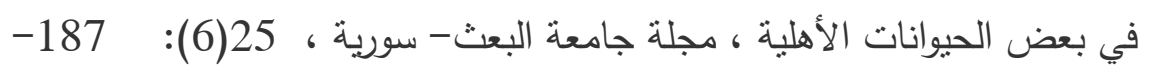
.182

هبو ، لقاء إبراهيم (1999): دراسة عن العدوى بداء المقوسات القندية (داء التوكسوبلازما) في الحيوانات والإنسان في حلب، رسالة ماجستير ، كلية العلوم- جامعة حلب. سورية.

\section{المراجع الإنكليزية English References}

Acha, P.N. and Szyfres, B. (1989): Zoonoses and Communicable Diseases Common to Man and Animals. Pan American Health Organization, Washington USA, 963 P. 
Benenson, M.W.; Takafuji, E.T.; Lemon, S.M; Greenup, R.L. and Sulzer, A.J. (1982): Oocysts transmitted Toxoplasmosis associated with ingestion of contaminated water. N. Engl. J. Med. 307: 666-669.

Benkirane, A.; Jabli, N. and Rodolakis, A. (1990): Fre'quence d'avortement et se' ropre' valence des principales maladies infectieuses abortives ovines dans la re'gion de Rabat (Maroc). Ann. Rech. Vet. 21: 267-273.

Beverley, J.K.A. and Watson, W.A. (1961): Further studies on Toxoplasmosis in Yorkshire sheep. Vet. Res. 73: 6.

Buxton, D.; Maley, S.W.; Wright, S.E.; Rodger, S.; Bartley, P. and Innes, E.A. (2007): Toxoplasma gondii and ovine toxoplasmosis: new aspects of an old story. Vet. Parasitol. 149: 25-28.

Caballero-Ortega, H.; Palma, J.M.; Garcl'aMa' rquez, L.J.; Gildo-Ca' rdenas, A. and Correa, D. (2008b): Frequency and risk factors for toxoplasmosis in ovines of various regions of the State of Colima, Mexico. Parasitology 135: 1385-1389.

Cook, A.J.C.; Gilbert, R.E.; Buffolano, W.; Zufferey, J.; Petersen, E.; Jenum, P.A.; Foulon, W.; Semprini, A.E. and Dunn, D.T. (2000): Sources of Toxoplasma infection in pregnant women: European multicentre casecontrol study. Br. Med. J. 321: 142-147.

Dubey, J.P. and Beattie, C.P. (1988): Toxoplasmosis of Animals and Man. CRC Press, Boca Raton, Florida, pp. 1-220.

Dubey, J.P. and Welcome, F.L. (1988): Toxoplasma gondii induced abortion in sheep. J. Am. Vet. Med. Assoc. 193: 697-700.

Dubey, J.P. and Kirkbride, C.A. (1984): Epizootics of ovine abortion due to Toxoplasms gondii in north central United States. J. Am. Vet. Med. Assoc. 184: 6, 657-660.

Dubey, J.P. (2009): Toxoplasmosis in sheep-The last 20 years, Veterinary Parasitology 163: 1-14.

Dume tre, A.; Ajzenberg, D.; Rozette, L.; Mercier, A. and Darde', M.L. (2006): Toxoplasma gondii infection in sheep from HauteVienne, France: seroprevalence and isolate genotyping by microsatellite analysis. Vet. Parasitol. 142: 376-379.

Eckert, J.; Friedhoff, K.T.; Zahner, H. and Deplazes, P. (2008): Lehrbuch der parasitologie fuer die Tiermedizin Enke Verlag Sstuttgart.

El-Ghaysh, A.A. and Mansour, M.M. (1994): Detection of antibodies to Toxoplasma gondii in an Egyptian sheep-herd using modern serological techniques. J. Egypt. Assoc. Immunol. 1: 117-121.

El-Metenawy, T.M. (2000): Seroprevalence of Toxoplasma gondii antibodies among domesticated ruminants at Al-Qassim Region, Saudi Arabia. Dtsch. Tiera" rztl. Wschr. 107: 32-33. 
EL-Moukdad, A.R. (2002): Serologische Untersuchung uber die pravalenz von Toxopplasma gondii bei Awassi-Schafen in syrien. Berl.Munch.Tierarztl. Wschr. 115: 173-178.

Feldman, H.A. and Amer J. Epidemiol (1965): 81:385-391

Figliuolo, L.P.C.; Kasai, N.; Ragozo, A.M.A.; De Paula, V.S.O.; Dias, R.A.; Souza, S.L.P. and Gennari, S.M. (2004): Prevalence of antiToxoplasma gondii and anti-Neospora caninum antibodies in ovine from Sa ̃o Paulo State, Brazil. Vet. Parasitol. 123: 161-166.

Fleck, D.G. and Kwantes, W. (1980): The Laboratory Diagnosis of Toxoplasmosis. London U.K., H.M. Stationary Office.

Freire, R.L.; Giraldi, N.; Vidotto, O. and Navarro, I.T. (1995): Levantamento soroepidemiolo' gico da toxoplasmose em ovinos na rgia o de Londrina, Parana'. Arquivos Brasileiro de Medicina Veterina' ria e Zootecnia 47: 609-612.

Frenkel, J.K. (1984): Toxoplasmosis in Hunter‘s Tropical Medicine"ed. Strickland, G.T., PP.593. W.B. Saunders Company: Philadelphia, London, Toronto, Mexico City, Roi de Janeiro, Sydney, Tokyo.

Frenkel, J.K. and Ruiz, A. (1981): Endemicity of Toxoplasmosis in Coctarica: Transmissiom between Cats, Soil, intermediate hosts and humans. Am. J. of Epidemiology, 133(3): 254.

Garcia, J.L.; Navarro, I.T.; Ogawa, L. and de Oliveira, R.C. (1999): Soroprevalência do Toxoplasma gondii, em su1'nos, bovinos, ovinos e equ" inos, e sua correlac,a a com humanos, felinos e caninos, oriundos, de propriedades rurais do norte do Parana' Brasil. Cie^ncia Rural. 29: 91-97.

Ghoneim, N.I.I.; Marzouk, M.A.; Mowafy, L.E. and Siam, M.A. (1984): Toxoplasmosis as a cause of genital Toxoplasmosis in Egypt. Vet. Med. J. 23: 3.

Gorman, T.; Pablo Arancibia, J.; Lorca, M.; Hird, D. and Alcaino, H. (1999): Seroprevalence of Toxoplasma gondii infection in sheep and alpacas (Llama pacos) in Chile. Prev. Vet. Med. 40: 143-149.

Harps, O. (1993): Untersuchungen u" ber die Seropra"valenz von Toxoplasma- Infektionen bei kleinen Wiederka"ueren in Jordanien. D.V.M. Thesis. Hannover, Germany, pp. 1-137.

Hashemi-Fesharki, R. (1996): Seroprevalence of Toxoplasma gondii in cattle, sheep and goats in Iran. Vet. Parasitol. 61: 1-3.

Hoghooghi-Rad, N. and Afraa, M. (1993): Prevalence of toxoplasmosis in humans and domestic animals in Ahwaz, Capital of Khoozestan Province, South-West Iran. J. Trop. Med. Hyg. 96 (3): 163-168. 
Hubbert, W.T.; Mcculloch, W.F. and Schnurenberger, P.R. (1975): Diseases Transmitted from Animals to Man. Charles C. Thomas Publisher, Springfield, Ilonois 6th Ed., U.S.A., 1206 P.

Jenum, P.A; Kapperud, G.; Stray-Pedersen, B.; Melby, K.K.; Eskild, A. and ENG, J. (1998): Prevalence of Toxoplasma gondii specific immunoglobulinG antibodies among pregnant women in Norway: Epidemiol. Infect., 120: 87-92.

Kean, B.H.; Kimball, A.C. and Christenson, W.N. (1969): An epidemic of acute Toxoplasmosis. J. Am. Med. Assoc., 208: 1002-1004.

Lappalainen, M.; Koskela, P. and Hedman, K. et al. (1992): Incidence of primary Toxoplasma infections during pregnancy in southern Finland: A prospective cohort study. Scand J. Infect Dis; 24: 97-104.

Lebech, M. Larsen, SO. and Petersen, E. (1993): Prevalence, incidence and geographical distribution of Toxoplasma antibodies in pregnant women in Denmark. Scand. J. Infect. Dis.; 25: 751-6.

Luft, B.J. and Remington, J.S. (1983): Toxoplasmosis. in Infectious Diseases ed. Hoeprich, P.D.PP.1133. Harper \& Row Puplishers: Philadelphia, Cambridge, New York, Hagerstown, San Francisco, London, Mexico, Sao Paulo, Sydney.

Lunde'n, A.; Carlsson, U. and Na"slund, K. (1992): Toxoplasmosis and border disease in 54 swedish sheep flocks-Seroprevalence and incidence during one gestation period. Acta Vet. Scand. 33: 175-184.

Lunde'n, A.; Na"sholm, A. and Uggla, A. (1994): Long-term study of Toxoplasma gondii infection in a Swedish sheep flock. Acta Vet. Scand. 35: 273- 281.

Mainar, R.C.; De la Cruz, C.; Asensio, A.; Domı'nguez, L. and Va'zquezBoland, J.A. (1996): Prevalence of agglutinating antibodies to Toxoplasma gondii in small ruminants of the Madrid region, Spain, and identification of factors influencing seropositivity by multivariate analysis. Vet. Res. Commun. 20: 153-159.

Martin, S.W. (1987): Veterinary Epidemiology. Hand Book, Pages 30-35. USA..

Mehlhorn, H. and Piekarski, G. (2002): Grundriss der parasitenkunde 6Auf. Gustav fischer verlag Stuttgart. Jena .

Perry, B.D.; Mogollon, J.D.; Grieve, A.S. and Galvis, A.L.H. (1979): Serological study of ovine Toxoplasmosis in Colombia epidemiological study of a field outbreak. Vet. Rec. 104, 11: 231-234. 
Ragozo, A.M.A.; Yai, L.E.O.; Oliveira, L.N.; Dias, R.A.; Dubey, J.P. and Gennari, S.M. (2008): Seroprevalence and isolation of Toxoplasma gondii from sheep from Sa o Paulo State. Brazil. J. Parasitol. 94: 1259-1263.

Rozette, L.; Dume'tre, A.; Couquet, C.Y. and Darde', M.L. (2005): Seroprevalence de la toxoplasmose chez des ovins et des bovins en Haute-Vienne. E' pide'miologie et Sante' Animale 48: 97-99.

Shaapan, R.M.; El-Nawawi, F.A. and Tawfik, M.A.A. (2008): Sensitivity and specificity of various serological tests for the detection of Toxoplasma gondii infection in naturally infected sheep. Vet. Parasitol. 153: 359- 362.

Verma, S.P.; Bhardwaj, R.M. and Gautam, O.P. (1988): Seroprevalene of Toxoplasma antibodies in aborted ewes. Indian J. Vet. Med. 8: 132-133.

Vesco, G.; Buffolano, W.; La Chiusa, S.; Mancuso, G.; Caracappa, S.; Chianca, A.; Villari, S.; Curro', V.; Liga, F. and Petersen, E. (2007): Toxoplasma gondii infections in sheep in Sicily, southern Italy. Vet. Parasitol. 146: 3-8.

Zeybek, H.; Yarali, C.; Nishikawa, H.; Nishikawa, F. and Du" ndar, B. (1995): The prevalence of toxoplasmosis in sheep of Ankara region. Etlik Vet. Mikrob. Derg. 8: 80-86 [in Turkish]. 